УДК 331.5

\title{
П.М. Лукичёв
}

\section{ТЕХНОЛОГИЧЕСКИЕ ИЗМЕНЕНИЯ И СОВРЕМЕННЫЕ РАБОТНИКИ СТАРШИХ BOЗРАСТОВ}

В статье рассматривается взаимосвязь между «постарением» рабочей силы и технологическими изменениями в современной экономике. Автор анализирует повышение спроса на роботов как в производстве, так и в обществе в связи увеличением числа работников старших возрастов. Повышение среднего возраста населения в развитых странах и в Российской Федерации уже является важнейшим фактором трансформации мировой экономики. «Поседение» рабочей силы вызывает необходимость изменений как организационных и управленческих решений на уровне предприятий, так и макроэкономической политики государства. Эти изменения должны оптимальным образом связать две реальные тенденции совершенствования современного производства: а) рост применения искусственного интеллекта, цифровой экономики, автоматизации и роботизации производственных процессов; б) старение рабочей силы во всех развитых странах и в Российской Федерации. Поддержка только одной тенденции не позволяет национальной экономике сохранять конкурентоспособность на мировом рынке. Автор на основе межстранового анализа выявляет новый подход к организации труда работников старших возрастов, опирающийся на современные технологии организации и управления персоналом на предприятии. Государство должно обеспечить создание благоприятной внешней среды для труда работников старших возрастов, позволяющей преодолеть неблагоприятные экономические и социальные последствия старения рабочей силы.

Ключевые слова: работники старших возрастов, технологии, роботизация, дискриминация по возрасту, государственное регулирование, политика управления трудовыми ресурсами.

DOI: $10.35634 / 2412-9593-2019-29-4-455-462$

В 2019 г. впервые на Земле людей старше 65 лет будет больше, чем в возрасте до пяти лет. Изменения, вызванные старением населения, окажут значительное воздействие и на экономику, и на общество в будущем.

Цель данной статьи - показать взаимовлияние старения работоспособного населения и развития современных технологий. Под технологией понимается применение научных знаний в практических целях, особенно в промышленности [1], или, в более широком смысле, технология относится к методам, системам и устройствам, которые являются результатом научных знаний, используемых в практических целях [2]. Таким образом, под технологией автор подразумевает не только технические, но и организационные улучшения. Отметим также междисциплинарный характер решения проблемы.

В наиболее явно взаимозависимость между технологическим развитием и современными работниками старших возрастов проявляется сегодня в увеличении применения роботов. В ряде развитых стран была выявлена чёткая корреляция между повышением среднего возраста работников и увеличением спроса на роботов. Abeliansky и Prettner выявили, что рост числа роботов на тысячу работников возрастает в 2 раза быстрее, чем падение роста населения. Это означает, что если население страны сокращается на $1 \%$, то рост количества роботов возрастает на 2\% [3]. Acemoglu и Restrepo обнаружили, что в период с 1993 по 2014 г. больше всего инвестировали в робототехнику страны, население которых стареет быстрее всего. Авторы придерживаются эмпирического правила: повышение коэффициента старения на 10 пунктов связано с увеличением количества роботов на 0,9 на тысячу рабочих [4]. По мнению Acemoglu и Restrepo, старением населения объясняется почти 40 \% различий в количестве роботов, представленных в стране. Существуют, на наш взгляд, две причины, объясняющие такую зависимость. Первая из них связана с необходимостью заменить труд тех, кто по возрасту покидает состав рабочей силы, и облегчить физический труд стареющих сотрудников. Вторая причина вызвана появлением растущего рынка по уходу за людьми, которые больше не могут заботиться о себе, и требующего применения медицинских и сервисных роботов.

При правильной общей тенденции, выявленной учеными, в национальном разрезе эта взаимозависимость не выглядит так радужно. Пример КНР, которая является крупнейшим производителем роботов с 36 \% мирового производства [5], показывает, что старение населения происходит быстрее, чем растет производство роботов. Кроме того, внутри даже «благополучных» по демографии разви- 
тых стран, таких как Великобритания и Франция, есть отрасли, где процент работников в возрасте, превышающем 50 лет, критический. В связи с этим структура парка производимых роботов, по нашему мнению, должна измениться. Во-первых, необходимо расширение использования роботов в ряде отраслей, критических по возрастной структуре работников. Во-вторых, необходим больший процент медицинских роботов и роботов по уходу за пенсионерами. Пока же промышленных робототехнических систем в 7 раз больше, чем «сервисных роботов», в которых только часть составляют медицинские роботы [6]. Если говорить конкретно, в 2018 г., по данным Международной федерации робототехники, в мире было продано около 20 тысяч роботов, применение которых так или иначе связано со старением населения. В их числе медицинские роботы, помощь инвалидам, экзоскелеты и т.П. Отметим в их развитии две тенденции. Число медицинских роботов за год выросло на 73 \% [7], хотя они и являются самыми дорогостоящими среди сервисных роботов. Количество силовых экзоскелетов человека, которые успешно используются для реабилитации и эргономической поддержки для снижения нагрузки, также имеет высокий потенциал роста.

Современная японская экономика характеризуется и другими проблемами. В Японии сейчас наиболее возрастное население и наибольшее число работающих после 65 лет. Внедрение роботов, обслуживающих пожилых людей, тормозится, помимо технологических проблем, тем, что пенсионеры хотят общаться с людьми, а не с роботами. В Японии существует сложная культура обслуживания, которую пытаются воспроизвести с помощью машин. Вместе с тем, по утверждению Й. Такеда, из исследовательского института Mitsubishi, японские клиенты, особенно пожилые люди, предпочитают людей машинам [8]. Нельзя сказать, что пожилые люди в Японии слишком привередливы. Дело в том, что робот, оказывающий физическую помощь пожилому человеку, может выполнять только одну задачу. Поэтому для решения нескольких задач необходимо значительное число роботов, что, с одной стороны, накладно, а с другой - требуется решить проблему по управлению всеми роботами. Кроме того, современные роботы и, в частности, их возможности распознавания образов, не на $100 \%$ надёжные. Если с этих позиций обратиться к реалиям России, то нужно отметить следующие основные проблемы. Во-первых, число роботов в России столь ничтожно, что Международная федерация робототехники не выделяет специально Россию, хотя упоминает, например, Вьетнам и Сингапур. Вовторых, в интересной статье Н.И. Комкова и Н.Н. Бондаревой, посвящённой обзору российского рынка робототехники, взаимосвязь между старением населения РФ и числом роботов даже не упоминается. Зато, по их мнению, потребуется «мультиквалификация потребителей для получения услуги через роботов. В РФ произойдёт бурный рост технологической компетентности населения» [9]. На наш взгляд, это предположение наивно. Оно согласуется с традиционным российским подходом: если дороги в России плохие, то надо не строить больше качественных трасс, а создавать автомобили и другую технику высокой проходимости.

Расширение применения новых технологий в производстве и, прежде всего, использования роботов и искусственного интеллекта катализирует «поляризацию рынка труда». На одном полюсе, назовём его «высший полюс», находятся рабочие места, требующие высшей квалификации: конструкторы, технологи, экономисты, инженеры, менеджеры, юристы. Именно для этой части работников требуется постоянная переподготовка по мере усложнения рабочих процессов, расширения использования искусственного интеллекта и в целом цифровой экономики. На другом - «низшем полюсе» находятся рабочие места, не требующие серьезного образования и сложных профессиональных навыков. Занятые на них выполняют, как правило, простую, рутинную работу. Более того, эта простая работа оплачивается сейчас так дёшево, что её невыгодно автоматизировать. Задерживает, «размывает» эту поляризацию расширение сферы услуг, требующих именно человеческого труда, поскольку многие представители старшего и среднего поколения предпочитают общаться с людьми, а не с обслуживающими роботами. Это временная, на наш взгляд, тенденция, поскольку в РФ и развитых странах подрастают дети, а в Японии уже подросли, которые предпочитают играть (общаться) с компьютерами, а не со своими сверстниками. В результате страны, роботизирующие производство в промежуточной сфере (между двумя «полюсами») и увеличивающие использование труда на «высшем полюсе», уходят вперёд в своём экономическом развитии и повышении уровня жизни. Страны же, медленно развивающие роботизацию и цифровизацию производства, предоставление услуг, отстают в улучшении жизни своих граждан. Роботизируя национальное производство по мере старения рабочей силы, страна получает возможность эффективно использовать преимущества работников старших возрастов - опыт, высокую квалификацию, профессиональные связи и нивелировать их недостатки. 
Технологические изменения и современные работники старших возрастов

457

ЭКОНОМИКА И ПРАВО

2019. Т. 29, вып. 4

Например, применение экзоскелетов работниками старших возрастов позволит повысить их физические нагрузки на рабочих местах.

Использование в производстве работников старших возрастов, помимо чисто технических проблем, требует новых подходов к организации и управлению их трудом на уровне предприятия и новых мер государственного регулирования рынка труда. Необходимость этого диктуется тем, что никогда ранее развитые страны и Россия не сталкивались с таким большим числом работников старших возрастов. Государственное регулирование [10] должно чётко определить важность (место) труда работников старших возрастов для национальной экономики и в зависимости от этого выработать меры адекватной макроэкономической политики. Здесь, по нашему мнению, возможны два диаметрально противоположных подхода. Первый связан с сохранением существующего положения дел, с представлениями, что работники старших возрастов не желают и не могут использовать новые технологии, становясь барьером для прогресса экономики. Тогда меры государственного регулирования должны быть направлены на стимулирование межпоколенческой конкуренции, на привлечение труда мигрантов. Например, Autor и др. [11] отмечали, что новые технологии заменяют для работников выполнение рутинных задач и дополняют для них решение нерутинных проблем и задач комплексных коммуникаций. Как следствие, требуются сотрудники, чтобы выполнять увеличивающееся разнообразие видов деятельности и приспосабливаться к новому определению их задач. В таком контексте приспосабливаемость становится главным фактором в производственном процессе и антивозрастное предубеждение из-за использования IT становится скорее постоянной, чем временной тенденцией. Второй подход связан с пониманием, что экономика сталкивается с трудностями развития главным образом из-за медленно растущей рабочей силы и быстро растущих пенсионных расходов. Поэтому меры государственного регулирования должны быть направлены на более длительное удержание людей на работе, в частности, путём увеличения пенсионного возраста. Для реализации второго подхода фирмам и организациям необходимо применять гибкие стратегии, которые побуждали бы работников старших возрастов оставаться на своих рабочих местах. Свою роль в этом должно сыграть и государство. Экономические выгоды государства от более позднего выхода на пенсию работников старших возрастов несомненны. Это и снижение расходов на пенсионные выплаты, уменьшение расходов на здравоохранение, финансируемых государством, снижение финансовой нагрузки на более молодых налогоплательщиков. Отсрочка выхода на пенсию даст государственному бюджету рост текущих налоговых поступлений, а работнику старших возрастов больше финансовых ресурсов при выходе на пенсию. Увеличение объема участия в рабочей силе работников старших возрастов снижает влияние стареющего населения на общество. Кроме чисто экономических выгод такого подхода, выделим повышение социальной значимости работников старших возрастов, снижение их изоляции от других поколений общества, возможность полностью реализовать заложенный в них потенциал.

В современной России государство пока явно придерживается первого подхода, связанного с сохранением сложившегося положения дел. Правительство отменило индексацию пенсий для работающих пенсионеров с целью ежегодной экономии 250 млрд руб. расходов бюджета. В результате краткосрочная экономия средств бюджета привела к долгосрочным потерям и для бюджета, и для населения РФ. 5,6 млн работающих пенсионеров прекратили работать, что привело к потерям казны от уплаты только налога на доходы физических лиц в размере 300 млрд руб. ежегодно и к потерям Пенсионного фонда, Фонда обязательного медицинского страхования и Фонда социального страхования в размере более чем 400 млрд руб. [12]. Социальный же урон для населения страны безмерен. Отметим, что это не чисто российское заблуждение в области макроэкономической политики. В Западной Европе и, в частности, в Голландии аналогичная политика, выработанная в 1970-е гг., привела к резкому уменьшению в последующие два десятилетия числа работающих работников старших возрастов. Однако с середины 1990-х гг. были проведены реформы программ социального обеспечения и пенсионных программ с целью создания более сильных стимулов для продолжения работы в зрелом возрасте, которые привели к расширению участия в производстве как мужчин, так и женщин старших возрастов [13]. Российскому правительству не нужно повторять ошибки 1970-х гг., а применять современную макроэкономическую политику, соответствующую реалиям сегодняшнего дня.

На уровне предприятий также необходимо применять гибкие стратегии, которые побуждали бы возрастных работников оставаться на своих рабочих местах. В первой статье, посвящённой эффективности труда работников старших возрастов [14], мы уже отмечали существование во всех странах дискриминации по возрасту. Дискриминация по возрасту, например, в Австралии её проявления на- 
зывают возрастными стереотипами [15], оказывает существенное негативное влияние на реальное решение проблемы. В частности, предписывающие стереотипы определяют нормативные ожидания в отношении поведения, на которые ссылаются, и невнимание к этим ожиданиям или их нарушение может приводить к конфликтам между поколениями [16]. Объективных научных данных, подтверждающих эти предубеждения против работников старших возрастов, не существует. На рабочих местах стереотипы поколений продолжают сохраняться, и Россия не является исключением. В то время как исследования, изучающие различия между поколениями, показали неоднозначные результаты, многие работодатели сообщают о различиях между поколениями и верят в существование распространенных стереотипов о различиях поколений на рабочем месте $[17 ; 18]$. Как и для других видов дискриминации - по полу, расе, исторически сложившиеся стереотипы не соответствуют изменившимся условиям. Применительно к данной теме предубеждения работодателей связаны со снижением когнитивных способностей, увеличением невыходов на работу из-за болезней, нежеланием осваивать новые технологии. Как отмечает Radford et al., исследования показали, что эти стереотипы не отражают фактической производительности труда и организационной приверженности пожилых сотрудников. Например, исследования, изучающие обоснованность стереотипов у пожилых работников, не обнаружили различий между пожилыми и более молодыми работниками с точки зрения их результатов работы [19]. Более того, другие исследователи обнаружили, что команды, включающие возрастных сотрудников, делали работу более качественно, хотя и немного медленнее, чем молодые работники [20]. Таким образом, для фирмы более выгодными при реализации проектов являются команды, составленные из разновозрастных сотрудников.

Тем не менее предубеждения работодателей относительно работников старших возрастов сохраняются. На практике эти возрастные стереотипы часто провоцируют обратную реакцию работников, как бы подтверждающую эти обвинения, и получается частично «самосбывающийся прогноз», закрепляющий, используя термин психологии, виктимность работников старших возрастов. Не случайно, как показывают исследования, пожилые люди, которые сталкивались с проявлением этих стереотипов на рабочем месте, сообщают об ухудшении памяти и когнитивных способностей, падении эффективности, снижении слуха и появлении сердечно-сосудистых стрессовых реакций [21].

Формирование на предприятиях команд из разновозрастных сотрудников должно опираться на объективные преимущества и недостатки, присущие в среднем каждому поколению. Для этого необходимо сравнение мотиваций, целей и навыков молодых работников и работников старших возрастов. Например, работники старших возрастов сообщают о более низкой вероятности увольнения, чем у более молодых работников [22; 23]. Таким образом, они с большей вероятностью останутся в своей организации до выхода на пенсию и более преданы ей, чем молодые сотрудники [24]. Кроме того, в большой выборке работников $(\mathrm{N}=747)$ более высокая эмоциональная (аффективная) приверженность и внутренняя мотивация сотрудников старших возрастов компенсировали возрастное снижение важности достижения целей [25]. С другой стороны, молодые работники (поколение Ү) имеют более высокие ожидания быстрого продвижения, более высокой оплаты и обучения, чем любое другое поколение [26]. В Турции молодые миллениалы оказались менее консервативными, чем работники поколения $\mathrm{X}$, и это влияет на их поведение на работе. Кроме того, сотрудники поколения Ү сообщили о более высоком желании работать в организации, потому что их индивидуальные цели и ценности во многом совпадают с целями и ценностями организации, в отличие от других поколений [27]. Также были обнаружены различия между поколениями в способности сотрудников решать многозадачные проблемы, работать в группах и в их потребности в немедленной обратной связи [28].

Следовательно, необходимо объективно признать существование различных целей в работе, способностей решать многозадачные проблемы, возможности работать в группах и их потребность в обратной связи, неодинаковых ожиданий карьерного продвижения, более высокой оплаты и обучения между представителями различных поколений. Из-за этого возникает потенциальный конфликт на рабочем месте и управленческие проблемы, связанные с рабочими стилями как работников старших возрастов, так и молодых работников. По нашему мнению, исходя из различий, реально существующих между работниками разных поколений, следует не противопоставлять их по принципу «кто лучше, кто хуже», а модифицировать политику управления трудовыми ресурсами на уровне фирм. Кроме того, надо постоянно помнить, что альтернатив более эффективного использования труда работников старших возрастов немного. Это или активнейшее применение робототехники, искусственного интеллекта, цифровой экономики, или усиление привлечения мигрантов. Но последнее порож- 
Технологические изменения и современные работники старших возрастов

459

ЭКОНОМИКА И ПРАВО

2019. Т. 29, вып. 4

дает целый ряд болезненных проблем, включая проблему второго поколения, размывание системы национальных ценностей, сохранение дискриминации.

Одним из важных аспектов проблемы старения населения являются обязанности по уходу сегодняшних работников за престарелыми родителями. Поскольку внедрение роботизации и автоматизации процессов здесь, как мы показали ранее, продвигается крайне медленно, то велика вероятность того, что работникам потребуется совмещать свою работу с предоставлением неоплачиваемой неформальной помощи своим престарелым родителям. В результате политика фирм по отношению к таким сотрудникам должна меняться. Обязанности по уходу за престарелыми влияют как на работников, так и на организации, поскольку несовместимость между работой и ролями по уходу может создавать напряжение и прерывать выполнение обеих ролей. Долгосрочные обязанности по уходу могут способствовать текучести кадров [29], срыву карьеры, неполной занятости и снижению благосостояния [30]. Эти неблагоприятные воздействия на благополучие работников наиболее вероятны, когда человек, получающий помощь, имеет плохое здоровье [31]. Поэтому на уровне предприятий и на уровне государства должны быть разработаны меры, позволяющие сгладить остроту этой проблемы. Самая радикальная форма государственного регулирования в данном случае - законодательно ввести оплачиваемые больничные по уходу за престарелыми, как по уходу за детьми. Но поскольку речь идёт о длительном уходе и отсутствуют чёткие критерии, то должны рассматриваться формы частичной занятости (или удалённой занятости) ухаживающих за престарелыми родителями. Именно поэтому на уровне фирм необходимо определить стратегии привлечения и удержания работников старших возрастов и работников, затронутых старением населения.

В целом сохранение и привлечение работников старших возрастов должно опираться на новые технологии организации и управления персоналом. Государственное регулирование может задать нужный вектор изменений, как это сделало, например, правительство Австралии, предлагающее до 10000 долларов фирмам, которые нанимают и удерживают работников старше 50 лет [32]. Однако государство, как мы указывали ранее [10], не может заменить собой деятельность предприятий. Фирмы должны выработать и применить новый подход к управлению работниками старших возрастов. Этот подход должен быть основан на следующих основных принципах. Во-первых, инициатива должна исходить от менеджеров компании, поскольку исследования показали, что негативные стереотипы в отношении возраста могут оказать существенное влияние на производительность. Начинать нужно с самого простого. Как предложили Billett, Dymock, Johnson и Martin [33], хорошим первым шагом в разработке политики по удержанию работников старших возрастов станет прекращение называть их «пожилыми работниками», так как этот термин вызывает предположения и вопросы о ценности, которую они представляют для организации. Менеджеры компании должны первыми избавиться от сложившихся негативных предубеждений о возрасте. В связи с этим Perry, Golom и McCarthy [34] отмечают, что простое указание сотрудникам воздерживаться от стереотипных суждений не является эффективной стратегией профилактики и может фактически привести к тому, что все большее число сотрудников примут стереотипные представления о работниках старшего или более молодого возраста. Вместо этого авторы предполагают, что применение позитивных стереотипов, противодействующих общепринятым негативным (например, прилежные работники более молодого возраста или работники старшего возраста, хорошо разбирающиеся в технологиях), является более эффективным подходом к минимизации воздействия негативных стереотипов. Соответственно, сотрудники старших возрастов, которые могут проявлять большую свободу действий в своей работе и в своём обучении, смогут продемонстрировать большую ценность для своей фирмы. Во-вторых, новый подход должен быть основан на том, что для поддержания возрастного разнообразия внутри организации надо учитывать различные требования как работников старших возрастов, так и молодых сотрудников. Дело в том, что при различных мотивах и стремлениях работников старших возрастов, представляется невозможным предположить [35], что стратегия удержания, которая применяется для молодых работников, будет эффективна для пожилых работников. В-третьих, необходима индивидуализация подхода, то есть к каждому отдельному работнику, а не к отрасли или предприятию в целом. Некоторые работники старших возрастов могут быть мотивированы остаться за счёт финансовых стимулов, но многие сотрудники, особенно те, кто работал в отраслях и профессиях с высокими доходами, гораздо реже остаются в компании, которая может предложить им только дополнительные денежные выгоды. Эти работники могут быть более мотивированы внутренними наградами, такими как расширение возможностей учиться или возможности полнее реализовать себя. В частности, предоставление возможностей обучения для работников старшего воз- 
раста считается менее важным, чем для работников более молодого возраста, и это может привести к тому, что пожилые сотрудники будут чувствовать себя менее значимыми и искать работу в других местах. Фирмы, сосредоточенные на программах обучения среди работников старших возрастов, вероятно, окажут положительное влияние на коэффициент удержания. Таким образом, чрезмерное упрощение мотивации работников старших возрастов может привести к неэффективным стратегиям. Необходимо, как предлагают Oakman and Wells [36], политику HRM (управления человеческими ресурсами) разрабатывать с учетом сложности решений о выходе на пенсию, если фирмы хотят успешно удерживать работников старших возрастов, а эффективные стратегии будут ориентированы на человека, а не на всю организацию. Следовательно, как в развитых странах, так и в РФ существует большая потребность в разработке эффективных политик управления персоналом, направленных на удержание сотрудников старших возрастов.

Для России решение данной проблемы, помимо слабой макроэкономической политики, отягчается ещё одной негативной особенностью. В России «обвал» экономической активности происходит после наступления пенсионного возраста: 60 лет у мужчин и 55 лет - у женщин. Тем не менее за последние 20 лет экономическая активность старшего поколения в России возросла на 11 п. П., что существенно больше, чем в развитых странах (6 п. п.) и тем более в развивающихся странах Европы (4 п. п.). Россияне старшего возраста перестают работать не из-за недостатка навыков: согласно исследованию ЕБРР, пожилые россияне по количеству необходимых для работы компетенций не отстают от лидеров - японцев и существенно опережают жителей других развитых стран, тем более жителей посткоммунистических государств. Проблема, как отмечал С. Гуриев [37], заключается в оценке людьми старших возрастов своего здоровья. Россияне моложе 50 лет чувствовали себя так же хорошо или даже лучше, как их ровесники в развитых странах. Но после 50 лет самооценка здоровья у российских мужчин резко снижается - до среднего уровня других развивающихся стран и намного ниже развитых. Следовательно, существующая в РФ система здравоохранения является фактором, сдерживающим развитие экономики страны.

Усиление тенденции старения рабочей силы принципиально модифицирует современный рынок труда и особенно взаимосвязь «развитие технологий - замещение труда». Увеличение количества работников старших возрастов в общем числе занятых порождает противоречивые экономические и социальные последствия. Экономические последствия связаны с сохранением численности занятости в национальной экономике на приемлемом уровне и с уменьшение нагрузки на государственный бюджет. Социальные последствия со знаком «плюс»: снижение изоляции работников старших возрастов от других поколений и возможность полностью реализовать их потенциал. Социальные последствия со знаком «минус»: сохраняющаяся дискриминация по возрасту, снижение статуса работников старших возрастов, недоиспользование потенциально ёмкого сегмента трудовых ресурсов. Последнее лишает экономику РФ одного из факторов развития совместимости с развитыми странами. Для того чтобы добиться эффективного использования потенциала работников старших возрастов, необходимо на уровне государства изменить регулирование этого сегмента рынка труда и на уровне фирм разработать новые стратегии управления сотрудниками старших возрастов и их организации.

\section{СПИСОК ЛИТЕРАТУРЫ}

1. Oxford Dictionary of English (3 ed) / Ed. by A. Stevenson. Oxford: Oxford University Press, 2010.

2. Collins English Dictionary. Thirteenth Edition. Glasgow: Harper Collins Publishers, 2018.

3. Abeliansky A., Prettner K. Automation and Demographic Change // Working Paper 05 2017, University of Hohenheim, Faculty of Business, Economics and Social Science. 34 p.

4. Acemoglu D., Restrepo P. Demographics and Automation // MIT Department of Economics Working Paper. March 7. 2018. № 18-05. Available at SSRN. URL: https://ssrn.com/abstract=3138621, http://dx.doi.org/10.2139/ssrn.3138621

5. Executive Summary World Robotics 2018 Industrial Robots. URL: https://ifr.org/downloads/press2018/Executive Summary_WR_2018_Industrial_Robots.pdf

6. Robots look after grandma // The Economist. February $16^{\text {th }} .2019$. P. 54-55.

7. Executive Summary World Robotics 2018 Service Robots. URL: https://ifr.org/downloads/press2018/Executive Summary_WR_Service_Robots_2018.pdf

8. Human endurance // The Economist. November $10^{\text {th }} .2018$. P. 57.

9. Комков Н.И., Бондарева Н.Н. Перспективы и условия развития робототехники в России // МИР (Модернизация. Инновации. Развитие). 2016. Т. 7, № 2. С. 8-21. doi: 10.18184/2079-4665.2016.7.2.8.21 
10. Лукичев П.М. Государственное регулирование аграрной сферы: дис. ...док. экон. наук / СПб гос. ун-т. СПб., 2000.

11. Autor D., Levy F., and Murnane R. The skill content of recent technological change: an empirical investigation // Quarterly Journal of Economics. 2003. Vol. 118 (4). P. 1279-333.

12. Сергеев М. Пять миллионов граждан ушли в тень // Независимая газета. 2019. 10 февр. URL: http://www.ng.ru/economics/2019-02-10/1 7503 five.html?utm referrer=https \%3A \%2F \%2Fzen.yandex.com

13. Kalwij A., Kapteyn A., de Vos K. Why Are People Working Longer in the Netherlands? // NBER Chapters. 2018. in: Social Security Programs and Retirement around the World: Working Longer National Bureau of Economic Research, Inc. 34 p.

14. Лукичёв П.М. Занятость работников старших возрастов: ресурс или ноша? // Вестник Удмуртского университета. Сер. экономика и право. 2018. №5. С. 641-646.

15. Radford K., Chapman G., Bainbridge H. T. J., Halvorsen B. The ageing population in Australia: Implications for the workforce. Ins. Werth, \& C. Brownlow (Eds.), Work and Identity: Contemporary Perspectives on Workplace Diversity. 2018. P. 39-54.

16. Finkelstein L., Truxillo D., Fraccaroli, F., Kanfer, R. (Eds.). Facing the challenges of a multi-age workforce: A useinspired approach. New York, NY: Routledge, 2015.

17. Lyons S., Kuron L. Generational differences in the workplace: A review of the evidence and directions for future research // Journal of Organizational Behavior. 2014. Vol. 35(S1), S.139-157.

18. Zacher H. Successful aging at work // Work, Aging and Retirement. 2015. Vol. 1(1). P.4-25.

19. Brough P., Johnson G., Drummond S., Pennisi S., Timms C. Comparisons of cognitive ability and job attitudes of older and younger workers // Equality, Diversity and Inclusion: An International Journal. 2011. Vol. 30(2). P. 105-126.

20. Gellert F.J., Kuipers B.S. Short- and long-term consequences of age in work teams: An empirical exploration of ageing teams // Career Development International. 2008. Vol. 13(2). P. 132-149.

21. Levy B.R., Slade M.D., Gill T.M. Hearing decline predicted by elders' stereotypes // The Journals of Gerontology. Series B: Psychological Sciences and Social Sciences. 2006. Vol. 61(2). P. 82-87.

22. Larrabee J.H., Wu Y., Persily C.A., Simoni P.S., Johnston P.A., Marcischak T.L., Gladden S.D. Influence of stress resiliency on RN job satisfaction and intent to stay // Western Journal of Nursing Research. 2010. Vol. 32(1). P. 81-102.

23. Reitz O.E., Anderson M.A., Hill P.D. Job embeddedness and nurse retention // Nursing Administration Quarterly. 2010. Vol. 34(3). P. 190-200.

24. Howe A.L., King D.S., Ellis J.M., Wells Y.D., Wei Z., Teshuva, K.A. Stabilising the aged care workforce: An analysis of worker retention and intention // Australian Health Review. 2012. Vol. 36(1). P. 83-91.

25. Heidemeier H., Staudinger U. Age differences in achievement goals and motivational characteristics of work in an ageing workforce // Ageing \& Society. 2015. Vol. 35. Is. 4. P. 809-836.

26. Moore S., Grunberg L., Krause A. J. Generational differences in workplace expectations: A comparison of production and professional workers // Current Psychology. 2015. Vol. 34(2). P. 346-362.

27. Lub X. D., Bal P. M., Blomme R. J., Schalk, R. One job, one deal... or not: Do generations respond differently to psychological contract fulfillment? // The International Journal of Human Resource Management. 2016. Vol. 27(6). P. 653-680.

28. Lai K.W., Hong K.S. Technology use and learning characteristics of students in higher education: Do generational differences exist? // British Journal of Educational Technology. 2015. Vol. 46(4). P. 725-738.

29. Bainbridge H.T.J., Broady T.R., Fong M. Addressing social exclusion: The role of individualized funding in facilitating employment // Journal of Business and Management. 2016. Vol. 22. P. 23-38.

30. Bainbridge H.T.J., Broady T.R. Caregiving responsibilities for a child, spouse or parent: The impact of care recipient independence on employee well-being // Journal of Vocational Behavior. 2017. Vol. 101. P. 57-66.

31. Kulik C.T., Cregan C., Bainbridge H.T.J. I feel your pain: The moderating effect of care recipient health on the relationship between work hours and care recipient and caregiver psychological outcomes // Analyses of Social Issues and Public Policy. 2013. Vol. 13(1). P. 114-136.

32. Australian Bureau of Statistics. 6202.0-Labour Force Australia, March 2017. Canberra: ABS.

33. Billett S., Dymock D., Johnson G., Martin G. Overcoming the paradox of employers' views about older workers // The International Journal of Human Resource Management. 2011. Vol. 22(06). P. 1248-1261.

34. Perry E. L., Golom F. D., McCarthy J. A. Generational differences: Let's not throw the baby boomer out with the bathwater//Industrial and Organizational Psychology. 2015. Vol. 8(3). P. 376-382.

35. Heidemeier H., Staudinger U. M. Age differences in achievement goals and motivational characteristics of work in an ageing workforce // Ageing \& Society. 2015. Vol. 35(4). P. 809-836.

36. Oakman J., Wells, Y. Working longer: What is the relationship between person-environment fit and retirement intentions? //Asia Pacific Journal of Human Resources. 2016. Vol. 54(2). P. 207-229.

37. Ломская Т. Сергей Гуриев рассказал, почему россияне старшего возраста перестают работать // Ведомости. 2018. 23 окт. 
Лукичёв Павел Михайлович, доктор экономических наук, профессор ФГБОУ ВО «Балтийский государственный технический университет “ВОЕНМЕХ” им.Д.Ф. Устинова» 190005, Россия, г. Санкт-Петербург, ул. Красноармейская, 1

E-mail: komdep@bstu.spb.su

\section{P.M. Lukichev \\ TECHNOLOGICAL CHANGES AND MODERN EMPLOYEES OF SENIOR AGE}

DOI: $10.35634 / 2412-9593-2019-29-4-455-462$

This article discusses the relationship between the "aging" of labor and technological changes in the modern economy. The author analyzes the increase in demand for robots both in production and in society due to an increase in the number of older workers. Increasing the average age of the population in developed countries and the Russian Federation is already a major factor in the transformation of the world economy. The "graying" of the labor force necessitates changes in both organizational and managerial decisions at the enterprise level and in the macroeconomic policy of the state. These changes should optimally link two real trends in the improvement of modern production: a) the growth in the use of artificial intelligence, automation and robotization of production processes, the digital economy; b) the aging of the labor force in all developed countries and the Russian Federation. Supporting only one trend does not allow the national economy to remain competitive in the global market. The author, on the basis of inter-country analysis, reveals a new approach to the organization of labor of older workers, based on modern technologies of organization and personnel management in the company. The state should ensure the creation of a favorable environment for the work of older workers, which allows to overcome the adverse economic and social consequences of the aging workforce.

Keywords: employees of senior age, technologies, robotization, age discrimination, government regulation, human resources management policy.

Lukichev P.M., Doctor of Economics, Professor at Department of "Management of the organization" Baltic State Technical University "Voenmech" named after D.F. Ustinov Krasnoarmeyskaya st., 1, Saint Petersburg, Russia, 190005

E-mail: komdep@bstu.spb.su 